\title{
El lugar de la mujer en el Partido Obrero Socialista. Chile, 1912-1922
}

The role of women in the Socialist Workers Party. Chile, 1912-1922

Jorge Navarro López

\begin{abstract}
RESUMEN
Este trabajo tiene por finalidad analizar el rol de las mujeres y el tratamiento de la problemática femenina al interior del Partido Obrero Socialista en el período 19121922. A través de la prensa partidista, se propone dar cuenta de los principales temas en que se ocuparon las/los socialistas y sus particularidades en las ciudades donde este partido logró influencia en el movimiento obrero.
\end{abstract}

Palabras Clave: mujeres socialistas, Partido Obrero Socialista, politización femenina, relaciones de género, movimiento obrero.

\section{AbSTRACT}

The purpose of this work to analyze the role of women and the treatment of women's issues within the Socialist Workers Party in the 1912-1922 period. Through the party press, an account is give an account of the main issues that the Socialists are occupied and their particularities in the cities where the party had influence in the labor movement.

KEYWORDS: Socialist Women, Socialist Workers Party, female politicization, gender relations, labor movement.

\footnotetext{
* Chileno. Magíster en Historia (Universidad de Santiago de Chile). Estudiante del Doctorado en Historia de la Universidad de Santiago de Chile. Correo electrónico: jorgenavarrolopez@gmail.com. Una parte de la información de este artículo fue reunida en el contexto de la tesis para optar al grado de Magíster en Historia titulada "La construcción de la cultura política del Partido Obrero Socialista. Factores, elementos y particularidades de la acción socialista, 1912-1918" (2015); sin embargo, tanto la exposición de los temas como las conclusiones aquí expuestas son exclusivas del presente trabajo.
}






\section{Introducción}

El objetivo de este artículo es indagar sobre el lugar que ocuparon las mujeres en la historia del Partido Obrero Socialista (POS). Con este propósito, examinaremos las acciones de las militantes en su proceso de politización y, también, analizaremos las representaciones femeninas que el discurso socialista difundió durante el período 19121922.

El POS se fundó a mediados de 1912, a partir de la escisión de un grupo de trabajadores salitreros militantes del Partido Democrático (PD), fenómeno que rápidamente se expandió por las principales ciudades de Chile. Los militantes que produjeron este quiebre lo hicieron con la intención de llevar a cabo una política rupturista de orientación clasista y socialista, objetivo que comprendían que no podía ser desarrollado al interior del $\mathrm{PD}$, por el actuar sistémico que este partido venía desarrollando a comienzos del siglo XX.

A pesar que la política formal contenía un veto explícito para las mujeres (sin posibilidad de votar en todas las elecciones hasta 1949) ${ }^{1}$, éste no fue un espacio extraño a la actuación femenina, ni tampoco a sus reivindicaciones. Desde comienzos del siglo XX es posible apreciar iniciativas que perseguían instalar las problemáticas femeninas en la opinión pública. Ya fuera desde los sectores dominantes (clubes de Damas o de lectura) o desde el mundo popular (sociedades obreras y mutuales), las mujeres aspiraban a lograr notoriedad pública para sus reivindicaciones.

Como fuera, las empresas políticas femeninas fueron más bien escasas hacia la primera década de 1900. En este sentido, es necesario analizar el papel que tuvo la mujer en el campo socialista, uno de los proyectos de politización al interior del mundo obrero (y que logró una importante proyección durante el siglo XX, a través de su continuador, el Partido Comunista), en tanto que el POS perseguía una visión igualitaria en el mundo del trabajo con la finalidad de proyectarla a la sociedad en su conjunto. Por tanto, si al interior del socialismo del período 1912-1922 se dio cabida a los temas femeninos, creemos posible integrar esta historia a las fuentes del feminismo de izquierda como una manifestación contra-hegemónica a la visión de género imperante en la sociedad chilena de comienzos del siglo XX.

En el mundo popular, la mujer debía coexistir con las dificultades propias de la escasez de recursos económicos, además de vivir bajo la presión de una sociedad marcadamente dominada por los hombres (y que muchas mujeres, a su escala, también reproducían). A pesar de las dificultades que estas condiciones entrañaban, es posible apreciar la incipiente participación política de las mujeres hacia fines del siglo XIX, principalmente a través de la sociabilidad artesanal y del $\mathrm{PD}^{2}$.

\footnotetext{
${ }^{1}$ Sobre el desarrollo del sufragio en Chile, ver Ricardo Nazer y Jaime Rosemblit, "Electores, sufragio y democracia en Chile: una mirada histórica", Mapocho, n ${ }^{\circ} 48$, Santiago, segundo semestre de 2000, pp. 215228.

${ }^{2}$ Es lo que se puede extraer de las reseñas biográficas de mujeres recogidas por Osvaldo López, en su Diccionario biográfico obrero, Santiago, Imprenta y Encuadernación Bellavista, 1912.
} 
Hacia la segunda mitad de la década del 1900, surgen, desde grupos de trabajadoras asociadas a la corriente socialista del PD, organizaciones que perseguían la integración del componente femenino a las luchas de la clase obrera. Las autoras que se han ocupado del tema, coinciden en que en estos casos es posible identificar a obreras con conciencia de clase, capacidad organizativa y con un alto grado de politización ${ }^{3}$. No obstante, difieren en cuanto al fondo del discurso obrero femenino y sus proyecciones en la lucha de los trabajadores. Para Elizabeth Hutchison, la labor de las mujeres demócratas-socialistas estuvo determinada por la solidaridad de clase, es decir, subsumieron las reivindicaciones estrictamente feministas a las exigencias de la liberación de los trabajadores, sin cuestionar mayormente el paternalismo de la dirigencia masculina ${ }^{4}$. En cambio, María Angélica Illanes inscribe estas experiencias (las que denomina como "vanguardia femenina") como parte de un objetivo mayor, en tanto que la búsqueda del concurso de sus pares masculinos estaría en función de la emancipación histórica del conjunto de la clase obrera, y por lo tanto, de las mujeres populares 5 .

Respecto al tema específico de la relación entre las mujeres y el POS, Julieta Kirkwood plantea que el acercamiento del POS a la problemática femenina se efectuó en clave clasista, resaltando la importancia de las características sociales de la pampa salitrera y el rol de Luis Emilio Recabarren en este proceso ${ }^{6}$. Julio Pinto también ha destacado el papel movilizador que le cabe a Recabarren en cuanto a la integración del ala femenina al conjunto de las actividades partidistas, proceso que estaría marcado por los ideales anticlericales. Además, entre los socialistas de Tarapacá, la apelación a la mujer estuvo influenciada por una visión regenerativa de las costumbres obreras, espacio donde la mujer debía cumplir un papel fundamental. Con todo, este autor destaca el rol del POS en la instalación de las reivindicaciones femeninas en una sociedad hegemonizada por los temas masculinos $^{7}$. En tanto, y matizando el rol femenino, Sergio Grez plantea que la militancia socialista fue abrumadoramente masculina, lo que implicó que las mujeres tuvieran una "débil implantación" al interior del partido ${ }^{8}$. Por otra parte, Isabel Torres al estudiar el tratamiento que una parte de la prensa del POS dio a la problemática femenina, señala su

\footnotetext{
${ }^{3}$ Elizabeth Hutchison, Labores propias de su sexo. Género, política y trabajo en Chile urbano, 1900-1930, Santiago, Lom Ediciones, 2006, pp. 121-149, y María Angélica Illanes O., Nuestra historia violeta. Feminismo social y vidas de mujeres en el siglo XX: una revolución permanente, Santiago, Lom Ediciones, 2012, pp. 13-26.

${ }^{4}$ Hutchison, op. cit., p. 149.

${ }^{5}$ Illanes, op. cit., p. 17.

${ }^{6}$ Julieta Kirkwood, Ser política en Chile, Santiago, Lom Ediciones, 2010, pp. 83-85.

7 Julio Pinto, "Socialismo y salitre: Recabarren, Tarapacá y la formación del Partido Obrero Socialista", Historia, vol. 32, 1999, pp. 360-362; Julio Pinto, "El despertar del proletariado: El Partido Obrero Socialista y la construcción de la identidad obrera en Chile", Hispanic American Historical Review, 86:4, 2006, pp. 707745; y Julio Pinto y Verónica Valdivia, ¿Revolución proletaria o querida chusma? Socialismo y Alessandrismo en la pugna por la politización pampina (1911-1932), Santiago, Lom Ediciones, 2001, pp. 4446. El planteamiento de Pinto y Valdivia respecto al anticlericalismo y su labor en el acercamiento de las mujeres al POS (propiciado por la figura de Recabarren), coincide con lo expuesto por Julieta Kirkwood, op. cit., pp. 82-83.

${ }^{8}$ Sergio Grez, Historia del Comunismo en Chile. La era de Recabarren (1912-1924), Santiago, Lom Ediciones, 2011, pp. 72-75.
} 
escasez para el período 1919-1922 y cuando este tema aparece -casi exclusivamente en intervenciones de Recabarren, otra vez- la mujer es comprendida como un sujeto pasivo y sometido a la movilización masculina? .

A partir de estos trabajos surgen algunas interrogantes en relación al papel que tuvo la problemática femenina en el POS. Uno de ellas tiene que ver con la importancia de los espacios sociales donde se desenvolvieron los y las socialistas, ya que buena parte de la literatura disponible sobre el tema se centra en lo sucedido en el norte salitrero, y casi exclusivamente en Iquique, lo que conduce a perder la perspectiva del socialismo como un fenómeno nacional $\mathrm{y}$, por lo mismo, con diferencias locales. Unido a este punto, la exaltación de la figura de Recabarren reduce la politización socialista a la visión de uno de sus dirigentes, llevando el análisis del problema a sólo una de sus partes constitutivas. En otro sentido, la minimización del papel de las mujeres en el partido contrasta con las fuentes disponibles, ya que si bien es cierto que no fue uno de los temas donde el POS invirtió sus mayores esfuerzos, igualmente estuvo presente desde su formación ocupando una buena cantidad de páginas en la prensa partidista, expresando, a su vez, la existencia entre sus filas de importantes esfuerzos por politizar a las mujeres populares. Por último, más que ser una característica del período 1919-1922, la complementariedad de las mujeres en las luchas obreras estuvo presente desde la creación del POS, generando un interesante debate justamente en esos años.

A partir de lo anterior, creemos necesario profundizar en los temas que las mujeres socialistas pusieron en discusión, así como también en las reivindicaciones que el partido respaldó y los ideales femeninos que intentó difundir. Para lograr estos objetivos, utilizaremos la prensa socialista como fuente principal, ya que fue en este espacio donde las/los militantes desarrollaron su labor intelectual en función de los intereses y principios políticos del partido. También porque fue aquí donde los obreros socialistas reafirmaron su identidad y discutieron con sus adversarios (burgueses, Iglesia, demócratas, anarquistas, etc. ${ }^{10}$. Es posible encontrar en la prensa socialista los escritos que invocaban específicamente a la mujer, además de las actividades y los artículos redactados por las militantes del POS. Así, a través de su examen, se puede conocer el rol que cumplieron las mujeres en la construcción de la politización obrera de matriz socialista, además de establecer si participaron en el partido desde su formación o se integraron a él mediante la invocación de los militantes varones y, también, analizar cómo el POS trató el papel social de las mujeres y cómo comprendió el papel político que éstas tenían que jugar en la persecución del socialismo. Por todo esto, la prensa partidista constituye la fuente básica para conocer los componentes elementales de la cultura política socialista.

\footnotetext{
${ }^{9}$ Isabel Torres D., El imaginario de las elites y los sectores populares. 1919-1922, Santiago, Editorial Universitaria, 2010, pp. 156-159.

${ }^{10}$ Un interesante trabajo que analiza las principales características de la prensa obrera y los tópicos con que se instala en el espacio público, así como las diferencias entre la prensa "gremial" y "partidista", es el libro de Mirta Lobato, La prensa obrera, Buenos Aires, Edhasa, 2009. Si bien está enfocado en el mundo del trabajo de Buenos Aires y Montevideo (entre 1890 y 1958), el tratamiento que realiza la autora entrega importantes claves de interpretación para comprender los alcances y características de la prensa obrera en el contexto latinoamericano.
} 
Este trabajo está organizado en tres apartados que dan cuenta de manera cronológica del lugar que ocuparon las mujeres socialistas, proponiendo una periodización analítica para tratar esta temática. Comienza con el examen de los tres primeros años del POS, profundizando en el papel de las mujeres en el desenvolvimiento del partido en la esfera política y gremial. Durante 1912-1915 las mujeres socialistas participaron activamente de las acciones del partido (a pesar del rol complementario que se les asignaba) y fue constante el énfasis anticlerical con que la prensa trató la problemática femenina. El siguiente apartado analiza la tensión entre el discurso de la complementariedad femenina y la apelación clasista hacia las mujeres, profundizando en las particularidades de las diferentes secciones del partido y su influencia en la forma de abordar el tema entre 1915 y 1917. La última parte de este trabajo examina el desplazamiento desde la visión complementaria hacia un reconocimiento político de la mujer, en un contexto de agudización de la movilización obrera, fenómeno que es apreciable también en la organización gremial de las mujeres.

\section{El despertar de la mujer socialista, 1912-1915}

La irrupción del POS en el sistema político chileno marcó el inicio de una serie de aspectos novedosos. La impugnación política estrictamente clasista, la necesidad de unir las reivindicaciones laborales con la política institucional, la proyección y lucha por construir el socialismo, fueron tal vez los fenómenos más destacados. En el centro de la actividad política del POS estaba el obrero, entendido como aquel sujeto explotado por el sistema capitalista que debía demostrar en el espacio público su capacidad para redimirse y, luego, remediar las desigualdades sociales y económicas. La política, que fue comprendida por el POS como el espacio fundamental de la esfera pública, se conjugaba la mayor de las veces en masculino. Como parte integrante de su época, los socialistas expresaban también las características de una sociedad que negaba importantes espacios a las mujeres. Sin embargo, la visión igualitaria de la propuesta política socialista se enfrentaba con el paternalismo dominante en la sociedad chilena de la segunda década del siglo XX. Y como un importante número de mujeres eran también trabajadoras, el discurso y la práctica socialista no podían dejarlas de lado.

El POS se creó a mediados de 1912, a partir del quiebre con el PD que llevó a cabo un grupo de demócratas-socialistas de Iquique. El órgano periodístico de los disidentes era El Despertar de los Trabajadores, publicado en esa ciudad y con fuerte presencia en las oficinas salitreras de la pampa de Tarapacá. Este periódico comienza el tratamiento de las problemáticas femeninas incluso antes de fundado el nuevo partido. A menos de un mes de existencia, se publicó un reportaje sobre el movimiento sufragista femenino en Estados Unidos, lamentando al mismo tiempo su proyección negativa para la realidad chilena, porque aquí «todavía, sinceramente, no lo hemos conseguido ni los hombres de verdad» ${ }^{11}$. La crítica al sistema electoral chileno, una constante en la prensa socialista, tiene en este

${ }^{11}$ El Despertar de los Trabajadores, Iquique, 30 de enero, 1912. 
artículo una aproximación novedosa. Aunque tratada todavía de manera parcial, la incorporación del sufragio femenino a los desafíos de la democratización, es un interesante preámbulo a la incorporación de las mujeres a la acción socialista.

Como hemos mencionado, la "cuestión femenina" había surgido entre los demócratas-socialistas a comienzos del siglo XX, gracias a la iniciativa de las mujeres que publicaron los periódicos La Alborada (Valparaíso, 1905-1906 y Santiago, 1906-1907) y La Palanca (Santiago, 1908) ${ }^{12}$, de las cuales Recabarren era cercano. Es lo que manifiesta este dirigente en una carta de 1913, donde solicitaba a sus compañeros de la capital que intentaran convencer a la tipógrafa Carmela Jeria -creadora de La Alborada- de trasladarse al norte salitrero para desempeñarse como obrera en la imprenta del POS y también como propagandista socialista. Estimaba Recabarren que dado el avance del socialismo en el norte salitrero, «cada día que transcurre se hace necesario disponer aquí de mayores elementos de combate. Por esta razón se me hace necesario contar aquí con la Carmela» ${ }^{13}$. Como deja ver la carta, Recabarren veía a Carmela Jeria como un(a) igual, respetándola como obrera y agitadora, precisamente las características esperadas para la clase obrera consciente convocada por los socialistas. No obstante este temprano gesto de reconocimiento a la labor efectuada por las mujeres, hay que precisar que esta noción de mujer-obrera/mujer-agitadora no fue extendida en los comienzo del POS, dado que entre los socialistas surtía efecto el sentido común hegemónico que exaltaba los rasgos sensuales femeninos y su supuesta debilidad.

Si bien en la asamblea de fundación del POS no se consigna la participación de alguna mujer, en las actividades partidistas rápidamente destacó la figura de Teresa Flores. A comienzos de 1913, Flores se dirigió junto a Recabarren a Antofagasta en una gira de propaganda, en la cual pronunció conferencias en diferentes oficinas salitreras vinculando los temas de la mujer con el socialismo. Fue en ese contexto que ambos dirigentes socialistas compartieron con la reconocida conferencista anticlerical española Belén de Sárraga. Bajo el impulso que dejaron las conferencias de Sárraga, Flores organizó, a su regreso al puerto de Iquique, el Centro de Mujeres Librepensadoras, que posteriormente adoptaría el nombre de la intelectual española. En su invitación inaugural, este centro anunciaba que su objetivo principal sería «la emancipación de las conciencias [femeninas] del tiránico yugo eclesiástico que tantos males causa a la humanidad» ${ }^{14}$. En la práctica, este centro funcionó como el ala femenina del POS iquiqueño ${ }^{15} \mathrm{y}$, prontamente, comenzó a participar de otras instancias organizativas promovidas por los socialistas, como mítines y conferencias al interior de la pampa salitrera, la Cámara del Trabajo y la Sociedad Obrera Cooperativa de Pan, además de destacarse en las manifestaciones del $1^{\circ}$ de mayo de $1913^{16}$.

No obstante la expectación que creó el Centro Femenino, los socialistas no comprendían todavía a las mujeres como pares y proyectaban su lugar en la lucha por el

\footnotetext{
${ }^{12}$ Hutchison, op. cit. e Illanes, op. cit.

${ }^{13}$ Archivo Histórico Nacional, Fondos Varios, vol. 1157, Epistolario Recabarren, carta de Luis E. Recabarren a Carlos A. Martínez, Iquique, 20 de abril, 1913.

${ }^{14}$ El Despertar de los Trabajadores, Iquique, 15 de abril, 1913.

${ }^{15}$ Julio Pinto, Luis Emilio Recabarren. Una biografía histórica, Santiago, Lom Ediciones, 2013, p. 128.

${ }^{16}$ El Despertar de los Trabajadores, Iquique, 3 de mayo, 1913.
} 
socialismo de forma complementaria a la labor de los obreros. Se les reservaba, eso sí, un papel primordial en el plano cultural, bajo la idea de la necesidad que las mujeres populares se alejaran de la influencia de la Iglesia. Es lo que expresaba el obrero salitrero José Zuzulich -uno de los fundadores del POS- cuando hacía mención a la mujer como «aquella que las leyes y la Iglesia han relegado a ser esclava de los quehaceres domésticos y ser pasto del capricho y voluptuosidad de los hombres, esa mujer, esa esclava, se levanta hoy altiva y fiera, para disputar al dragón romano su libertad y dignidad por tantos siglos explotada». Si bien en el texto se infiere que Zuzulich comprendía la dominación masculina como un problema de género, se mantenía en su análisis una visión paternalista de la mujer, por ello, en un intento por destacar su valor, las definía como «ese Ser que endulza en el hogar nuestras horas de reposo, con sus cariños y cuidados, aquella madre que incansable lucha por dar a sus hijos los goces que lo hagan feliz» ${ }^{17}$.

En los primeros años del POS, la apelación a las mujeres estuvo estrechamente relacionada con los efectos de la religión. A pesar de esto, la actuación de las militantes socialistas excedió el plano anticlerical. Así lo dejó claro Teresa Flores en una asamblea de la sociedad de resistencia de zapateros y aparadoras, en donde llamó a las trabajadoras de este gremio a esforzarse por sostener en el tiempo la organización obrera, para que en conjunto con la educación, las mujeres se encaminaran hacia la independencia económica y cultural $^{18}$.

La autonomía planteada por Flores no fue refrendada discursivamente por sus compañeros. En una exhortación que en 1913 El Despertar de los Trabajadores realizaba a las mujeres, se proponía un tipo de movilización obrera subordinada necesariamente a lo realizado por los hombres. Entendiendo al socialismo como «la única doctrina que transforma a los hombres», el periódico solicitaba a las mujeres realizar acciones para acercar a padres, hermanos, esposos e hijos al partido, porque a través de ese camino «vuestros sufrimientos se acabarán», como una de las consecuencias de la conversión socialista masculina $^{19}$. Este efecto positivo del socialismo en las condiciones de vida de las mujeres, fue entendido de manera similar por los militantes puntarenenses, quienes veían en el trabajador socialista una personalidad culturalmente superior, afianzado en su núcleo familiar, ajeno al maltrato físico a su pareja e hijos y fuera del alcance del alcohol. Por lo mismo, señalaban que para «los socialistas, el hombre que maltrata a sus hijos, a su compañera, es un ser miserable, una bestia incapaz de sentir amor y de comprender la dignidad de la familia, al cual se debe separar de su seno por ser indigno de pertenecer a ella» ${ }^{20}$.

Así, hacia el primer cuarto del siglo XX, la integración de las mujeres populares a la vida pública debía no sólo salvar los escollos de una sociedad que las marginaba, sino que también debían enfrentarse a un discurso hegemónico que las veía como un apéndice del sujeto masculino y del cual los obreros organizados no escapaban del todo. Sin duda, las

\footnotetext{
${ }^{17}$ El Despertar de los Trabajadores, Iquique, 10 de mayo, 1913.

${ }^{18}$ El Despertar de los Trabajadores, Iquique, 20 de mayo, 1913.

${ }^{19}$ El Despertar de los Trabajadores, Iquique, 9 de septiembre, 1913.

${ }^{20}$ El Socialista, Punta Arenas, 31 de enero, 1915.
} 
acciones de las mujeres socialistas contribuyeron a ir derribando los prejuicios machistas presentes entre sus mismos compañeros. Este fue uno de los propósitos de la movilización femenina del POS, la cual tuvo diferentes características según las particularidades locales de los movimientos obreros a los cuales se vinculaba.

A fines de 1913 un grupo de mujeres socialistas creó en Valparaíso la Sociedad El Despertar de la Mujer, la cual, con un discurso con menos tintes anticlericales y un signo más clasista que en Iquique, se proponía «albergar en su seno a la mujer obrera para emanciparla de los prejuicios sociales de que es víctima por la sociedad burguesa» ${ }^{21}$. El discurso que pronunció a fines de enero de 1914 su vicepresidenta, la militante socialista Lucila Aravena de Vergara, reafirmó la orientación clasista de esta organización. En su disertación, Aravena concebía al trabajo como una instancia propia tanto de hombres como de mujeres, situación que históricamente había decantado hacia la subordinación de las segundas. Denunciaba también la doble explotación que afectaba a las mujeres trabajadoras. No se trataba de la doble explotación femenina en la fábrica y en el hogar, sino de la referencia a la prostitución, uno de los principales focos críticos de las/los socialistas y en la que identificaban la sumisión extrema de la explotación capitalista. Para solucionar esto, Aravena señalaba la necesidad «que nos levantemos airadas, para exigir justicia a los acaparadores de la riqueza social ${ }^{22}$. Es decir, insubordinarse en contra de la dominación de la burguesía. La naciente organización femenina porteña fue secundada desde sus inicios por el dirigente Víctor Roa Medina, quien a comienzos de 1914 expresaba que la «sociedad burguesa se sentirá inquieta cuando la dócil sierva se rehúse al dogma y a la servidumbre, proclamando en cambio la libertad del pensamiento y el derecho a la honra que se le niega». Por lo mismo, para Roa era necesario promover la organización de las mujeres, «porque su libertad importa la muerte de la sociedad presente y el triunfo de la sociedad futura» ${ }^{23}$.

Siguiendo este impulso organizativo, hacia febrero de 1914 se creó en Viña del Mar otra sección de El Despertar de la Mujer. Era ésta una plaza importante para el POS, debido a que en este polo industrial trabajaba una gran cantidad de mujeres ${ }^{24}$. Tras la huelga general de octubre de 1913 en Valparaíso y Viña del $\mathrm{Mar}^{25}$, los socialistas advirtieron prontamente la relevancia de los trabajadores de la Refinería de Azúcar y de la Fábrica de Tejidos Gertry (conocida como Fábrica de Paños y Tejidos). Bajo este diagnóstico intentaron aumentar su influencia en estas industrias -especialmente entre las obreras

\footnotetext{
${ }^{21}$ La Defensa Obrera, Valparaíso, 22 de noviembre, 1913. Quizás motivada por la similitud en el nombre con la organización iquiqueña, Elizabeth Hutchison atribuye erróneamente a Recabarren y Teresa Flores la fundación de esta sociedad obrera femenina. Hutchison, op. cit., 154.

${ }^{22}$ La Defensa Obrera, Valparaíso, 31 de enero, 1914.

${ }^{23}$ La Defensa Obrera, Valparaíso, 31 de enero, 1914.

${ }^{24}$ Para conocer una panorámica de la actividad industrial en esta ciudad a comienzos del siglo XX, ver los artículos de María Ximena Urbina, "Chalets y chimeneas: los primeros establecimientos industriales viñamarino, 1870-1920" Archivum, Viña del Mar, año IV, no 5, 2003, pp. 173-196 y de Eugenia Garrido, "Los orígenes de Viña del Mar y su proceso de industrialización. Un caso específico: Lever, Murphy y Cía.", Archivum, Viña del Mar, año V, no 6, 2004, pp. 74-87. Ambos disponibles en internet: http://arpa.ucv.cl/

${ }^{25}$ Sobre los motivos y alcances de esta huelga ver Eduardo Godoy, La Huelga del Mono. Los anarquistas y las movilizaciones contra el retrato obligatorio (Valparaíso, 1913), Santiago, Quimantú, 2014.
} 
textiles-, promoviendo la organización gremial de los/las trabajadores e intensificando las conferencias en las cercanías de estas fábricas. Durante este período fue común la participación de las militantes socialistas como oradoras en los mítines de desocupados y de protesta política que se desarrollaban en Valparaíso, como fue el caso de Soledad Zurriaga $^{26}$.

En este contexto, los socialistas porteños publicaron un artículo de Isolina Borquez $^{27}$ en donde planteaba que las mujeres eran esclavas de la religión, del capital y del matrimonio, situación que debía transformarse al alzar éstas su voz para reclamar por sus «legítimos derechos, nunca tenidos en cuenta y eternamente desconocidos por los usurpadores (Sanguijuelas) del proletariado». Pese a esta inicial invocación clasista, Borquez centraba su crítica en la Iglesia y en el papel que le cabía en la subordinación femenina. Y si bien reprochaba al matrimonio por situar a la mujer «como objeto de placer, como máquina de hacer hijos o esclava doméstica, sin derecho a manifestar gustos ni opiniones», de igual forma adoptaba un discurso de exaltación maternal, al exigir a sus compañeras el cumplimiento de la «alta misión de formar hombres libres, de iniciativa y de gran impulso intelectual» ${ }^{28}$. Una idea similar expresaba la anteriormente nombrada Lucila Aravena en un discurso pronunciado en marzo de 1914. En aquella oportunidad, esta dirigente identificaba que «todo el engranaje del régimen burgués» operaba para reprimir el avance social y cultural de las mujeres, las cuales debían situarse «al lado de nuestros esposos y nuestros hijos que con el corazón firme llevan en sus fornidos brazos los estandartes de la paz y la justicia», en ardua lucha «contra los prejuicios, contra la mentira religiosa y política» ${ }^{29}$.

Similares argumentos había ocupado un tiempo atrás la socialista iquiqueña Rosario Vargas de Barnes, cuando planteaba, en el contexto de las discusiones sobre una futura organización femenina, que «sin perturbar su gran misión en el hogar, la mujer puede y debe cooperar a la obra de su propia emancipación moral y material» ${ }^{30}$. A través de estos ejemplos, podemos apreciar que la correlación entre la crítica anticapitalista y la apelación al carácter complementario de la mujer en la lucha obrera, era bastante extendida y no sólo se encontraba presente entre los socialistas varones.

A pesar de estos esfuerzos, la organización de las mujeres trabajadoras no avanzaba en todas partes con la misma intensidad. A fines de 1914, Eloísa Pérez escribía al director

\footnotetext{
${ }^{26}$ Sobre la participación de esta integrante de El Despertar de la Mujer en una manifestación organizada por la Sociedad Pro Carpinteros Desocupados y en otra a favor de la instrucción pública, organizada por la Federación de Estudiantes de Valparaíso, ver El Chileno, Santiago, 10 de noviembre, 1914 y La Unión, Valparaíso, 18 de enero, 1915, respectivamente.

${ }^{27}$ Se trata de una activa propagandista en temas relativos a las mujeres. En esa calidad, publicó artículos en diarios socialistas y anarquistas, por lo mismo, no ha sido posible establecer fehacientemente su militancia. En este caso, más allá de si Borquez fue o no socialista, importa el hecho de que los socialistas porteños publicaron sus artículos, haciéndose parte de su interpretación. Los textos de Isolina Borquez publicados en la prensa anarquista en Adriana Palomera y Alejandra Pinto (comp.), Mujeres y prensa anarquista en Chile (1897-1931), Santiago, Ediciones Espíritu Libertario, 2006, pp. 95-96 y 103-104.

${ }^{28}$ La Defensa Obrera, Valparaíso, 7 de marzo, 1914.

${ }^{29}$ La Defensa Obrera, Valparaíso, 13 de marzo, 1914.

${ }^{30}$ El Despertar de los Trabajadores, Iquique, 15 de abril, 1913.
} 
de El Socialista de Punta Arenas reclamando por la falta de organización entre las trabajadoras. Argumentaba que a muchas de ellas «les importa un comino que en los talleres las exploten, no piensan jamás que también nosotras, al igual que los obreros, podemos organizarnos en sociedades de resistencia y exigir por nuestro trabajo una más justa remuneración». A su juicio, esa situación se debía a que ninguna organización se preocupaba de «proteger a la mujer obrera de los desmanes de sus explotadores». Frente a esto interpelaba al director socialista: «ipor qué la Federación Obrera [de Magallanes], que tantos beneficios ha conseguido para sus asociados, no se preocupa de nosotras? ¿Y los socialistas, que nos reconocen y luchan porque tengamos los mismos derechos económicos y políticos que los hombres, [por qué] no toman la iniciativa?» ${ }^{31}$. La crítica de Eloísa Pérez hacía eco de la actuación de la Federación Obrera de Magallanes (FOM), que tras la huelga general de 1912 había conseguido firmar convenios colectivos anuales, en donde se aseguraban reajustes salariales y condiciones mínimas para sus asociados, que en su mayoría se desempeñaban en las estancias ganaderas, una labor exclusivamente masculina. Además, Pérez apelaba a la declaración de principios de los socialistas puntarenenses, que contenía una reivindicación explícita a la igualdad civil entre ambos $\operatorname{sexos}^{32}$, dejando de manifiesto a su vez la distancia entre discurso y práctica socialista que percibían las mujeres cercanas al movimiento obrero, y también la debilidad de la agrupación de Punta Arenas frente a la hegemonía de la FOM.

A la luz de nuestros tiempos es posible que la postura de los y las socialistas no deslumbre, pero contrastada con las propuestas de otros grupos sociales de la época aparece como un avance notable respecto a las posiciones que existían en torno a la problemática femenina. La revista Familia, publicación mensual dirigida a las mujeres de la elite chilena, divulgaba por aquella época un discurso que asociaba las preocupaciones de las mujeres con la moda, las labores domésticas y el deber ser de la esposa. Su edición de septiembre de 1914, hacía alusión al feminismo definiéndolo, eso sí, como una moda pasajera frente a la cual muchas chilenas se encontraban discutiendo «las más graves cuestiones para sacudir el yugo». La editorialista recomendaba a sus lectoras que, en lugar de seguir esta "moda", se mantuvieran ocupadas en sus hogares, ya que «la felicidad verdadera de la mujer está en el hogar». Por lo mismo, debían esforzarse por «ser siempre la buena y cariñosa compañera del marido», «ser la que lo consuele, [ya que] en ella debe refugiarse para que lo aliente y con gracias y ternuras debe hacerle olvidar sus preocupaciones» 33 .

Este tipo de visión no era un atributo exclusivo de la elite oligárquica, sectores cercanos a los grupos medios también difundían la necesaria vinculación de la mujer con las labores domésticas, maritales y maternales. La sección "Página Femenina" del diario del Partido Radical La Razón (publicada entre marzo y abril de 1913), daba espacio a artículos que exaltaban estas características. "iQue se eleve la humilde, la más digna de apoyo, la obrera, hasta ser la madre ideal del hombre honrado!» ${ }^{34}$, se lee en uno de ellos. En una

\footnotetext{
${ }^{31}$ El Socialista, Punta Arenas, 27 de diciembre, 1914.

${ }^{32}$ El Socialista, Punta Arenas, 12 de julio, 1913.

${ }^{33}$ Familia, Santiago, septiembre, 1914.

${ }^{34}$ La Razón, Santiago, $1^{\circ}$ de marzo, 1913.
} 
reproducción de una conferencia dirigida al público femenino, se planteaba que «si queremos poblar el mundo de grandes hombres, sabios, conscientes y buenos, instruyamos a la mujer» ${ }^{35}$. Otro ejemplo en este sentido es la Revista Industrial Femenina (1912-1914), publicación de la Escuela Profesional Superior, institución que perseguía capacitar a las futuras obreras industriales. Sin embargo, una rápida revisión de los tópicos tratados por esta revista, deja de manifiesto su intención de reforzar las labores domésticas y maternales entre las mujeres populares ${ }^{36}$.

Como vemos, al igual que en el caso de los socialistas, en estos ejemplos encontramos una lectura complementaria de la labor social de las mujeres, pero con profundas diferencias en cuanto a los fines de ese apoyo. Aunque parcial, una comparación como ésta nos permite vislumbrar el distanciamiento del sentido común de la época y los alcances políticos del discurso socialista respecto de las mujeres, que junto al tratamiento de los anarquistas al tema constituían las vertientes más radicales de la crítica sobre el estado de la mujer en la sociedad chilena de comienzos del siglo $\mathrm{XX}^{37}$.

La preocupación por los derechos civiles de las mujeres fue también un tema común entre los socialistas de todo el país. Ejemplo de ello fue el programa mínimo de los socialistas de Punta Arenas publicado a mediados de julio de 1913, que establecía como uno de sus objetivos primarios la igualdad civil entre hombres y mujeres. Si bien puede parecer una declaración de principios abstracta, los puntarenenses iban más allá y se declaraban partidarios de una ley de divorcio, de la protección legal de la maternidad, de la igualdad legal entre hijos "legítimos" e "ilegítimos" (nacidos dentro y fuera del matrimonio legal, respectivamente) y del derecho a la investigación de la paternidad, medidas que buscaban contrarrestar el recurrente desconocimiento de ésta entre los hombres ${ }^{38}$. Similares objetivos se planteaba, unos meses después, la plataforma electoral del candidato socialista a senador por Santiago, Juan de la Cruz Rojas, agregando a la igualdad civil, la igualdad política para las mujeres. Su programa ahondaba también en el tema de la paternidad, al plantear la declaración forzosa de ésta y la obligación del padre de dar una pensión para alimentos y proporcionar educación a los hijos ilegítimos ${ }^{39}$.

A comienzos de la década de 1910, Luis Zuloaga, socialista y licenciado en Derecho, se desenvolvía como un activo militante en la capital, organizando sociedades de resistencia y escribiendo crónicas sobre el movimiento obrero internacional y nacional. Zuloaga había obtenido su grado académico con el trabajo titulado De la prestación del

\footnotetext{
${ }^{35}$ La Razón, Santiago, 12 de abril, 1913.

${ }^{36}$ Sobre la labor de la Escuela Profesional en esta época, ver Hutchison, op. cit., pp. 190-195. La Revista Industrial Femenina fue digitalizada por la Biblioteca Nacional de Chile y se encuentra disponible en http://www.memoriachilena.cl/archivos2/pdfs/MC0024230.pdf.

37 Sobre las relaciones entre las mujeres y el anarquismo, ver Palomera y Pinto, op. cit.; Sergio Grez, Los anarquistas y el movimiento obrero. La alborada de "la idea" en Chile, 1893-1915, Santiago, Lom Ediciones, 2007, pp. 147-157; Adriana Palomera, "Subjetividad e identidad política y social de la mujer en la prensa anarquista de comienzos del siglo XX", Olga Ulianova (ed.), Redes políticas y militancias, Santiago, Ariadna-USACH, 2009, pp. 31-58.

${ }^{38}$ El Socialista, Punta Arenas, 12 de julio, 1913.

${ }^{39}$ La Voz Socialista, Santiago, 20 de octubre, 1913.
} 
trabajo en general y particularmente por los criados domésticos ${ }^{40}$. Es interesante este trabajo porque, en consonancia con la orientación de los socialistas de la época, relacionaba los problemas "económicos" con los de tipo "político", conectando la precariedad laboral de los trabajadores/as domésticos con la imposibilidad de ejercer sus derechos ciudadanos, dado que una de las causas para suspender el derecho a sufragio era desempeñarse en el servicio doméstico. Esta prohibición política adscrita al trabajo, reforzaba a su vez la exclusión electoral de las mujeres, ya que eran éstas precisamente la gran mayoría de quienes ejercían servicios domésticos ${ }^{41}$.

A pesar de estos esbozos de igualdad política para las mujeres, entre los socialistas continuó operando la noción de la mujer como un apoyo del obrero organizado políticamente, además, del énfasis puesto en su labor como madre y su papel en la formación de las generaciones venideras. Tampoco Recabarren escapaba a esta orientación. En un artículo de abril de 1914, señalaba que en lo venidero la labor de las mujeres estaría marcada por su rol como madres formadoras de los futuros luchadores: «El mañana es de la mujer. Porque ella es la que mecerá en su seno los seres componentes de la Humanidad Futura, cuyo esplendor ya divisamos y nos satisface siquiera concebirla. Madre-mujer, tu frente será el Sol futuro. [...] Tu regazo será el lecho perfumado del Hombre creador de la nueva vida» ${ }^{42}$.

Es probable que al comprender la participación de las mujeres en las elecciones como un escenario demasiado lejano, los socialistas no articularan con mayor proyección las demandas femeninas estrictamente políticas y se enfocaran en resaltar las labores domésticas culturales que podían realizar las mujeres bajo una orientación socialista. La exaltación de las características maternales en esta primera etapa, pudo ser también una estrategia para acercar a las mujeres populares a la causa socialista, intentando poner a disposición de éstas referentes sociales más afines y de fácil comprensión, mezclándolos a su vez con la promesa igualitaria del socialismo. Así también ocurrió con el discurso ético con que el partido buscó acercarse hacia los trabajadores hombres en sus primeros años, marcado por la exaltación del rol proveedor, de la honestidad y la valentía.

Respecto al escaso tratamiento del sufragio femenino, también hay que considerar la evaluación crítica de los socialistas sobre los vicios del sistema electoral y los efectos que tenían en él fenómenos como el cohecho y la intervención del Ejecutivo. No obstante ello, en sus primeros años, el POS propició la organización de las mujeres obreras y, en los gremios donde trabajaban tanto hombres como mujeres, las sociedades de resistencia bajo

\footnotetext{
${ }^{40}$ Luis Zuloaga, "De la prestación del trabajo en general y particularmente por los criados domésticos", Memoria de prueba para optar al grado de Licenciado en la Facultad de Leyes y Ciencias Políticas de la Universidad de Chile, Santiago, Imprenta de "El Pueblo", 1911.

${ }^{41}$ Una demostración de la extensión del servicio doméstico, es que entre 1885 y 1920 un 33,9\% de las mujeres trabajadoras de Santiago se desempeñaban en estas labores. Alejandra Brito, "Del rancho al conventillo. Transformaciones en la identidad popular femenina Santiago de Chile, 1850-1920", en Lorena Godoy, Elizabeth Hutchison, Karin Rosemblatt y M. Soledad Zárate (eds.), Disciplina y desacato. Construcción de identidad en Chile, siglos XIX y XX, Santiago, SUR-CEDEM, 1995, p. 54.

${ }^{42}$ El Despertar de los Trabajadores, Iquique, 30 de abril, 1914. Reproducido en en Ximena Cruzat y Eduardo Devés (comp.), Recabarren. Escritos de prensa. Tomo 3, 1914-1918, Santiago, Nuestra América y Terranova Editores, 1986, pp. 27-28.
} 
influencia socialista siempre llevaron la ampliación genérica "Ambos Sexos". Es decir, el foco del discurso y de la acción socialista estuvo en la organización de las mujeres en tanto trabajadoras, con un fuerte énfasis en los temas anticlericales y una casi inexistente apelación como sujeto electoral.

Sin embargo, y a pesar que no podían votar, las mujeres socialistas no se mantuvieron al margen de la agitación electoral que realizaba el POS. En el contexto electoral de 1915, los socialistas iquiqueños volvían a vincular el bienestar de las mujeres con el avance del socialismo y la influencia que tendría éste en el espacio doméstico. Así, cotidianamente invitaban a las mujeres "progresistas", si querían «ver más feliz y dichoso su propio hogar», a trabajar por el triunfo de los candidatos socialistas al Parlamento, ya que el POS era el único partido «que firmemente combate todos los vicios que producen las desgracias» ${ }^{43}$. Y no eran pocas las acciones que las socialistas realizaban para alcanzar estos fines. Hacia febrero de aquel año, Ana Gutiérrez, Ilia Gaete, Josefina Gaete, Adela de Lafertte, Idia Osorio, Mercedes Roco, Clarisa Riveros, Catalina Agüero y Teresa Flores eran conferencistas frecuentes en las jornadas de agitación electoral que organizaba el partido en la pampa salitrera ${ }^{44}$. En un escenario como éste, y a poco días de las elecciones, las militantes del Centro Femenino "Belén de Sárraga" instaban a sus congéneres a apoyar a los candidatos del POS: «Si queremos acción al verdadero liberalismo y moralidad, trabajemos por el triunfo del socialismo» ${ }^{45}$. Aunque no podían votar, el día de la elección las socialistas de Iquique salieron a la calle con carteles en los que se leía "Vender el voto es vender la familia", "No votéis por tus patrones", "Los pobres debemos unirnos", y mientras un pequeño grupo las aplaudía, «la inmensa mayoría de proletarios, ebrios de abyección, las insultaba groseramente» ${ }^{46}$.

Similar situación se vivía en Valparaíso, en donde el obrero ferroviario Luis González R. pronunció un discurso señalando la necesidad de educar a la mujer, cuyo primer paso en ese sentido debía ser el apoyo a los candidatos socialistas ${ }^{47}$. En otro mitin, la futura militante comunista Carmen Serrano declamó una poesía dedicada a los candidatos socialistas. En tanto, en su órgano de prensa, el POS porteño publicaba una delimitación política, aclarando que las mujeres que se interesaran por el «bienestar positivo del pueblo, deben hacer propaganda por los candidatos socialistas» ${ }^{48}$.

En síntesis, en sus primeros tres años el POS propició la participación política de las mujeres a través de la movilización obrera y anticlerical, con un discurso que enfatizaba el rol suplementario que les cabía en la lucha obrera de carácter socialista. Esta última característica era compartida por distintas capas sociales -como la elite y los sectores medios-, pero con la diferencia que el discurso socialista integraba la participación femenina en la construcción de una nueva sociedad para superar el capitalismo y sus consecuentes desigualdades, entre ellas, obviamente, las que afectaban directamente a las

${ }^{43}$ El Despertar de los Trabajadores, Iquique, 27 de febrero, 1915.

${ }^{44}$ El Despertar de los Trabajadores, Iquique, 28 de febrero, 1915.

${ }^{45}$ El Despertar de los Trabajadores, Iquique, 28 de febrero, 1915.

${ }^{46}$ El Despertar de los Trabajadores, Iquique, 9 de marzo, 1915.

${ }^{47}$ La Defensa Obrera, Valparaíso, 6 de febrero, 1915.

${ }^{48}$ La Defensa Obrera, Valparaíso, 27 de febrero, 1915. 
mujeres. A pesar de que a comienzos de la década de 1910 los espacios de participación femenina en la política institucional eran inexistentes, los socialistas comprendieron a las mujeres como un grupo esencial en la construcción de la sociedad futura. Es probable que la prohibición legal para que las mujeres participaran en las elecciones, haya influido en el carácter complementario que el discurso del POS les asignó a sus partidarias. Sin embargo, como hemos visto, las militantes socialistas participaron activamente en la política formal (elecciones), intervención que fue aceptada e impulsada por sus compañeros. Este tipo de práctica política situó a las socialistas en el espacio público de una manera distinta a lo manifestado por las mujeres de la elite. Las formas de participación política de las mujeres socialistas estaban en consonancia con la cultura política del POS, es decir, un proyecto rupturista basado en una visión clasista de la sociedad, pero con aspiraciones de desarrollarlo al interior del sistema institucional a través de las acciones de un partido político. A partir de estas variables las mujeres socialistas se situaron en el espacio político y gremial, ya fuera participando en la movilización electoral del POS o en las organizaciones obreras promovidas por el partido.

En los años venideros, y con el afianzamiento de la estructura partidaria, la problemática femenina continuó integrando el aparataje discursivo socialista, surgiendo nuevas temáticas y aspiraciones.

3. 1915-1917: entre el discurso de la complementariedad femenina y la profundización del discurso clasista

Tras las elecciones de 1915 y el Primer Congreso del partido (mayo de 1915), los socialistas reforzaron sus energías en el ámbito gremial, situación que se vio vigorizada además por el traslado a Valparaíso de importantes dirigentes nortinos. En este puerto, el POS disputaba palmo a palmo la hegemonía del movimiento obrero con los anarquistas y, como vimos, ya había logrado instalar la temática femenina con un discurso marcadamente obrerista, diferenciándose del énfasis anticlerical que se difundía en el norte salitrero.

Desde la publicación de El Socialista de Valparaíso, órgano oficial del POS, la problemática femenina se tornó más común en el discurso partidista. El primer número de este periódico (31 de julio de 1915) contenía dos artículos que incitaban a las mujeres a unirse a la lucha de los trabajadores. En el primero de ellos, se planteaba que uno de los objetivos fundamentales de la prensa obrera debía ser la concientización de las mujeres proletarias, emprendiendo «una campaña contra la explotación del trabajo femenino [...] que a la vez señale a las obreras el camino de la unión y de la asociación como único remedio contra la explotación». El segundo artículo, llamaba a las trabajadoras a «instruirse, organizarse, leer [...] para que entren a fraternizar, a discutir, a razonar y a darse cuenta de lo que les pertenece»; sucedido esto, «llegará la mujer a colocarse en el verdadero terreno que le corresponde como productora y contribuyente al progreso en todas sus manifestaciones ${ }^{49}$. Nos interesa destacar en estos escritos la instalación en la prensa

\footnotetext{
${ }^{49}$ El Socialista, Valparaíso, 31 de julio, 1915.
} 
oficial del partido de un discurso que estimulaba la autonomía gremial y política de las mujeres, ya que no se hace referencia a la labor de la mujer como acompañante en la lucha del hombre trabajador. En ambos artículos se apela directamente a las mujeres trabajadoras, enfocándose en los desafíos comunes a la lucha obrera.

Estos artículos fueron el preámbulo preciso para la formación, una semana después, de una nueva sociedad de resistencia que agruparía a los obreros de la Compañía Chilena de Tabacos y que adoptó el nombre de Unión de Elaboradores de Tabacos de Ambos Sexos. La sesión inaugural fue presidida por Recabarren y el acta constitutiva fue firmada por 26 mujeres y 36 hombres, ocupando el cargo de vocal la obrera Laura Urbina ${ }^{50}$. La organización de este gremio estuvo en el centro de las actividades de la segunda mitad de 1915 de la sección socialista de Valparaíso, poniendo especial cuidado en las conferencias semanales realizadas en las cercanías de la fábrica. A mediados de agosto, Recabarren se dirigió a las mujeres tabacaleras, llamando la atención sobre el rol que cumplía la organización en el mejoramiento de las condiciones laborales, sin la cual las mujeres terminarían a merced de «las fábricas y talleres que tragan insaciables, vida y belleza de jóvenes mujeres dignas de mejor suerte». Para remediar estos males, invitaba a las mujeres a unirse a la nueva sociedad de resistencia ${ }^{51}$. A la agitación del gremio tabacalero concurrieron también importantes dirigentes socialistas, como Teresa Flores, Víctor Roa M. y Ramón Sepúlveda L., este último organizando una sección viñamarina ${ }^{52}$. A mediados de octubre, la Unión de Elaboradores de Tabacos de Ambos Sexos contaba con más de doscientos afiliados, en su mayoría mujeres (además de hombres y niños del gremio) ${ }^{53}$, y su balance arrojaba un saldo positivo de $\$ 443$, más de la mitad por concepto de cuotas de los/las asociadas ${ }^{54}$.

La problemática femenina en el ámbito socialista se inauguró en 1916 con un artículo de Julia Arévalo, titulado "El derecho femenino" y publicado en Punta Arenas. En él, la autora hacía referencia a la igualdad parcial de la ley, que castigaba de forma equivalente a hombres y mujeres, imponiéndoles a éstas deberes que no eran replicados equitativamente con sus derechos, entre ellos, la posibilidad de establecer las mismas leyes que las castigaban. Arévalo instigaba a sus lectores a declararse como "feministas", entendiendo por ello una declaración en contra de la supremacía de un género por sobre otro. Agregaba que, si detrás de las intenciones de los socialistas estaba «la elevación moral e intelectual del pueblo», era necesario que se situara «a la mujer en el mismo nivel que al hombre»y, así, al pasar aquella a ser «dueña de sus derechos, conseguiremos la redención del pueblo» 55 .

La conexión entre los derechos de las mujeres y la acción socialistas no era nueva. Tras las elecciones de marzo de 1915, la socialista Ana Gutiérrez pronunció en Iquique una

\footnotetext{
${ }^{50}$ El Socialista, Valparaíso, 7 de agosto, 1915.

${ }^{51}$ El Socialista, Valparaíso, 21 de agosto, 1915.

${ }^{52}$ El Socialista, Valparaíso, 4 de septiembre, 1915.

${ }^{53}$ De acuerdo a las cifras reunidas por Elizabeth Hutchison (Tabla 11), en la industria del tabaco, entre 1912 y 1917, las mujeres ocupaban el 64\% de los puestos de trabajo. Hutchison, op. cit., p. 68.

${ }^{54}$ El Socialista, Valparaíso, 9 de octubre, 1915.

${ }^{55}$ El Socialista, Punta Arenas, 6 de enero, 1916.
} 
conferencia titulada "Los derechos de la mujer", en donde reclamaba la igualación de derechos para ambos sexos, impedida, según su interpretación, por la educación religiosa y la inferioridad que socialmente se le asignaba a las mujeres. Usando el ejemplo de la Declaración de los Derechos de la Mujer y la Ciudadana (redactada en 1791 por Olympe de Gouges como respuesta a la Declaración de los Derechos del Hombre y del Ciudadano), incitaba a las mujeres a asociarse para dar «de una vez el golpe de gracia a esas rancias y funestas costumbres que se oponen a nuestra libertad, a nuestra verdadera emancipación total». Según la lectura de Gutiérrez, la unión de las mujeres debía fundarse «en los modernos moldes del socialismo, único faro que ha de llevar a la Humanidad a su más amplio perfeccionamiento, a su más absoluta libertad». Al finalizar retomaba, como era costumbre, la apelación al carácter maternal de las mujeres: «Ya lo sabéis mujeres, [...] si queréis que vuestros derechos de madre sean respetados, cobijaos bajo esa bandera roja que trémula por todo el Orbe con esta enseña: SOCIALISMO!» ${ }^{56}$. Se puede apreciar nuevamente aquí la extensión del anticlericalismo entre las socialistas de Tarapacá, quienes, a diferencia de sus pares del centro y sur, hacían mayor hincapié en la influencia negativa que ejercía la religión sobre las mujeres. A pesar de que este era un tema común entre los socialistas, en los lugares donde el movimiento obrero era más diverso y mayormente concentrado en las ciudades (como en Valparaíso), el énfasis anticlerical cedía ante el discurso obrerista.

Debido a que hacia mediados de la década de 1910 la movilización obrera femenina en Santiago había decaído respecto a la década anterior, Esther Valdés de Díaz (experimentada militante demócrata-socialista y directora del periódico La Palanca publicado en 1908) realizaba a comienzos de 1916 una crítica tanto a la inacción femenina como al papel que les cabía a los varones asociados, en relación a la falta de participación de las mujeres en la organización obrera. Recriminaba a éstos el desinterés por promover el estudio de los problemas sociales entre las mujeres y la participación femenina en las sociedades, conferencias y bibliotecas obreras ${ }^{57}$. Unas semanas después arremetía nuevamente en contra de los varones organizados, señalando que «no es dejando a la mujer al cuidado de los quehaceres domésticos [...] como los hombres llevarán a cabo su programa de acción, de mejoramiento económico, moral e intelectual que señala como fundamento de existencia la organización obrera masculina» ${ }^{58}$. Las críticas de Valdés ponían en tela de juicio la coherencia entre el discurso y la práctica de los socialistas. Crítica que al parecer no fue internalizada con la debida profundidad por sus compañeros. Por ejemplo, Carlos A. Sepúlveda recogía positivamente las palabras de Esther Valdés y señalaba que la «mujer proletaria es la que recibe con más fuerza el azote de esta deficiente organización social»y, por lo mismo, debía «marchar a la vanguardia de nuestras organizaciones». Pero a pesar de esta declaración inicial, más adelante planteaba, estereotipadamente, que la mujer era necesaria en la lucha obrera «porque ella es la que con su juventud lo alegra todo, porque ella es la que prepara al hombre y a la mujer del futuro,

\footnotetext{
${ }^{56}$ El Despertar de los Trabajadores, Iquique, 30 de mayo y 2 de junio, 1915. Énfasis en el original.

${ }^{57}$ Acción Obrera, Santiago, $1^{\mathrm{a}}$ quincena de febrero, 1916.

${ }^{58}$ Acción Obrera, Santiago, $2^{a}$ quincena de febrero, 1916. Énfasis en el original.
} 
[...] porque ella es la que dirige el hogar, porque ella es la que se entiende con todos los gastos diarios» ${ }^{59}$. Las palabras de Sepúlveda expresan la tensión que existía en los socialistas entre el reconocimiento de las mujeres como agentes políticos y el rol primordial que se les asignaba en el ámbito doméstico, justamente lo que criticaba Esther Díaz.

En Valparaíso, en tanto, se verificaba un aumento de la influencia socialista en el movimiento obrero. A modo de preparación para la conmemoración del $1^{\circ}$ de mayo de 1916, Teresa Flores publicó un artículo donde situaba conjuntamente a hombres y mujeres en la lucha obrera. Según su apreciación, estas últimas exigían, «con justo derecho, la necesidad de participar de los beneficios que conquiste la acción proletaria», sin embargo, advertía que «para reclamar este derecho es preciso también que la mujer participe en la lucha redentora». De esta forma, reconocía la urgencia que el movimiento de reivindicaciones laborales integrara a las mujeres, una inclusión que debía darse por la acción femenina misma y ya no como un derivado de la lucha de los obreros hombres: «Hay centenares de problemas que afectan íntimamente a la mujer obrera, en los cuales tienen un lindísimo campo donde dar impulsos y resoluciones a estos problemas, sólo falta para esto que sea ella misma la incitadora». Para lograr beneficios, la mujer proletaria debía participar de las manifestaciones obreras, con la intención de «sacar el mayor provecho de estas conmociones públicas donde se alza el grito dolorido de toda una raza que gime bajo el imperio capitalista» ${ }^{60}$. Quizás influenciada por el ambiente obrero de Valparaíso, en donde ella era una de las más activas animadoras, Teresa Flores apelaba a las mujeres en tanto trabajadoras, dejando de lado su anterior preocupación anticlerical y, más importante aún, el rol complementario en la lucha obrera que el discurso socialista del período 19121915 les asignaba.

A diferencia de lo ocurrido en años anteriores en Valparaíso, la conmemoración del $1^{\circ}$ de mayo de 1916 presenta un visible aumento de la participación de militantes socialistas en esta importante conmemoración. En el mitin organizado por el partido Tránsito Meneses de Castro planteó, ante unos cuatro mil manifestantes, que los pobres tenían sólo dos caminos: «O rebelarnos contra la tiranía y la explotación que soportamos; o seguir aplastados por el despotismo y el hambre». También hablaron en dicha jornada Ana Gutiérrez, a nombre del Centro de Estudios Sociales, y Soledad Zurriaga, en representación de El Despertar de la Mujer. Esta última reclamó por la falta de participación femenina en una fecha tan importante para los trabajadores como el $1^{\circ}$ de mayo, ya que según su opinión la mujer debía participar en las manifestaciones obreras «para que se acostumbre a la lucha y se capacite en ella» ${ }^{61}$.

Hacia 1916 el POS comenzó un proceso de expansión por el país, que llevó a que importantes dirigentes de Valparaíso se dirigieran al norte salitrero y a Concepción. Uno de ellos fue Víctor Roa M., quien emprendió viaje a Taltal para afianzar la sección del partido en ese importante puerto salitrero de la provincia de Antofagasta. En esta ciudad publicó el periódico La Aurora, que recogió las preocupaciones que le eran ya comunes: participación

\footnotetext{
${ }^{59}$ Acción Obrera, Santiago, $1^{\mathrm{a}}$ quincena de marzo, 1916.

${ }^{60}$ El Socialista, Valparaíso, 29 de abril, 1916.

${ }^{61}$ El Socialista, Valparaíso, 6 de mayo, 1916.
} 
política de los obreros, enfrentamientos doctrinarios con demócratas y anarquistas, organización obrera e integración de la mujer a las filas socialistas. Bajo esa inspiración, en junio de 1916 realizó un sentido llamado a la mujer proletaria: «¡Luchar! Ésa es tu vida, ¡luchar para la vida! Sí. Luchas obrera en el taller, dejando tus pulmones, tu inteligencia y hasta tu pundonor en manos del que explota tus juveniles energías». Aclaraba, además, que su invocación era clasista, dado que la liberación que proclamaba era estrictamente para la mujer obrera. Finalizaba exponiendo sus intenciones de ver a la mujer obrera «libre de la explotación y el engaño [...] grande, muy grande, luchando con conciencia para la vida, para la vida realmente feliz en la organización de tu clase y de tu sexo» ${ }^{62}$. Un mes antes, y con motivo de la conmemoración del $1^{\circ}$ de mayo, su esposa, Sara Vergara de Roa, había publicado un saludo a las mujeres trabajadoras, el que finalizaba recordando la importancia de la prensa obrera: «Pensemos las obreras y busquemos en nuestros periódicos el valor de este día florido para los pobres» ${ }^{63}$.

Lo realizado por Roa en Taltal buscaba reforzar el todavía débil desarrollo del POS en Antofagasta, donde Luis Víctor Cruz publicaba desde 1916 El Socialista, periódico en el que aparecían artículos que abordaban el tema de la mujer con una visión menos emancipadora y enfocando el problema en la educación anticlerical y el apoyo que la mujer debía prestar al trabajador organizado. Ejemplo de esta orientación, es un artículo de febrero de 1918 que sostenía que la «mujer no sólo debe ser para el hombre la compañera que le dé hijos; debe ser [también] la esposa consciente que, con su inteligencia, secunde las obras del marido, y entonces el marido seguirá su marcha; y el porvenir sonreirá a todos; y será el engrandecimiento de las naciones; y habrá Paz y Justicia para todos» ${ }^{64}$. Como vemos, en el norte salitrero la visión de la problemática femenina continuaba apegada al rol complementario asignado a las mujeres obreras y la influencia que ejercía en éstas la educación religiosa. A este respecto, es importante destacar el discurso que Roa M. difundía en Taltal, comprendiendo el problema femenino desde una óptica clasista, más acorde con el enfoque que tenían los/las socialistas de Valparaíso.

Como fuera, con más o menos énfasis, en casi la totalidad del discurso socialista se destacaba el rol maternal de la mujer y su función cultural y política en relación a la educación de los hijos. Esto último no conducía necesariamente a asignarle a la mujer un rol secundario o prescindible en la acción socialista, sobre todo porque la maternidad era un referente social cercano para la mayoría de éstas a comienzos del siglo XX y, por lo tanto, una madre politizada podía ejercer una función de concientización que resultaba fundamental.

La penetración de la acción socialista y la orientación clasista de su discurso entre las mujeres obreras de Valparaíso, quedó de manifiesto en el llamado que en mayo de 1917 efectuó a sus compañeras de trabajo Luzmira Carril, obrera textil. Frente a los reiterados reclamos por las negativas condiciones laborales de las obreras de la Fábrica de Paños y Tejidos, Carril proponía a sus compañeras que lo «práctico sería que nos uniéramos todas y

\footnotetext{
${ }^{62}$ La Aurora, Taltal, 30 de junio, 1916.

${ }^{63}$ La Aurora, Taltal, $1^{\circ}$ de mayo, 1916.

${ }^{64}$ El Socialista, Antofagasta, 2 de febrero, 1918. Un artículo similar en la edición del 14 de febrero, 1918.
} 
formáramos una sociedad defensora de nuestros intereses y de nuestra existencia, y lucháramos todas juntas por nuestro bienestar y el de nuestra familia; así unidas nos haríamos respetar y no seríamos víctimas de tanta explotación y escarnio» ${ }^{65}$. De igual manera, Ivan Ardiff, socialista porteño, mezclaba la crítica a la pasividad femenina con la necesidad que ellas mismas fueran quienes cambiaran su posición subordinada. «La mujer, por iniciativa propia nunca indaga, nunca analiza lo que le presentan sus falsos educadores [religiosos] como verdad», y cuando llegaba a hacerlo, «la sociedad la condena, por desertora del regimiento oscurantista, al desprecio y al silencio». Así, el «problema que tienen que resolver las mujeres del presente es el de su educación, y deben hacer todo lo posible por alcanzar una educación racionalista», ya que la «mujer que logra romper con todos los prejuicios, estudia, piensa y pone en práctica su idea de justicia y libertad, es una mujer de progreso». Según sus palabras, los socialistas estaban «con las mujeres que se rebelan al medio ambiente mantenedor de los prejuicios, pasando por sobre todo hasta lograr imponerse» ${ }^{66}$. Es decir, de acuerdo a esta visión y la de Luzmira Carril, y parafraseando una cita de Marx que llamaba poderosamente la atención de los socialistas, la emancipación de las mujeres debía ser obra de las mujeres mismas.

Reforzando lo anterior, A. de Guafra dedicó dos artículos a reprochar el papel masculino en la lucha por la emancipación femenina. Dando una larga lista de ejemplos históricos donde la mujer había desempeñado un rol fundamental, de Guafra se lamentaba que en su época la mayoría de las personas comprendiera a las mujeres «como algo accesorio [...] sin importancia, sin voluntad propia, sin criterio». Según su interpretación, esta situación se fundaba en el desconocimiento de la mujer, principalmente por parte de los hombres. Por lo mismo, a «la mujer no la comprenderá jamás aquel que pasa y la empuja», ni tampoco quien «llega a conocerla en los burdeles», ni «el macho ahíto de placer», debido a que éstos «saben sólo que es voluble, caprichosa, sensual» e ignoraban a la mujer «verdadera, a esa que es inteligente, espiritual, apasionada». Recordaba que la mujer "verdadera" se había destacado en el ámbito político, gremial, cultural y artístico, y como reconocimiento tanto a su papel histórico como a su labor reivindicativa, proclamaba «Paso al Feminismo, que triunfe definitivamente» ${ }^{67}$.

Los ejemplos aquí expuestos, tanto los más conservadores como los más progresistas, dan cuenta de la existencia de una tensión al interior del POS respecto a la emancipación de las mujeres populares, mediada por la participación femenina en las organizaciones obreras y en el espacio político de la segunda década del siglo XX, aspectos fundamentales para los socialistas. En el norte salitrero, el rol complementario que se les asignó fue lo más frecuente. En cambio, en Valparaíso esta visión mutó hacia un discurso que les exigió el desarrollo de un camino autónomo, ya fuera en las reivindicaciones laborales o en su desarrollo cultural. No obstante, y teniendo en cuenta las particularidades de la vinculación del partido con los movimientos obreros en distintas ciudades, es posible observar que en estos primeros años el conjunto de los socialistas comprendió a la mujer

\footnotetext{
${ }^{65}$ El Socialista, Valparaíso, 17 de mayo, 1917.

${ }^{66}$ El Socialista, Valparaíso, 21 de julio, 1917.

${ }^{67}$ El Socialista, Valparaíso, 18 de agosto y $1^{\circ}$ de septiembre, 1917.
} 
como un sujeto importante para la construcción de la nueva sociedad que aspiraban construir (quizás no el primordial), ya fuera que realizara sus acciones autónomamente o como refuerzo de las realizadas por el obrero varón.

\section{Del reflujo al reconocimiento político de las mujeres socialistas, 1918- 1922}

Las elecciones de 1918 revelan un alejamiento del papel político de las mujeres socialistas. Como vimos, en 1915 la apelación al papel femenino en las elecciones fue una constante en las secciones socialistas, situación que no se repitió en 1918. Si bien en el centro del país, las plataformas electorales de las secciones de Santiago y Valparaíso integraban el reconocimiento de la igualdad civil de ambos sexos, en ninguna de las dos se incluía el derecho a voto para las mujeres ${ }^{68}$. Y cuando se invocó a las mujeres, el discurso retornó hacia la apelación de las obreras como reservorio moral de la familia: «Obreras! Vosotras, las víctimas sufridas, las madres, las esposas, las hermanas, las hijas, todas deberéis preguntar a aquellos que comercian con su voto: ¿si vendéis vuestra conciencia acaso no vendéis la felicidad de todos nosotros?» ${ }^{69}$. Para las elecciones de 1918, la participación femenina en los actos de propaganda disminuyó considerablemente. Por ejemplo, en Iquique y en Antofagasta los encargados en los discursos en las proclamaciones y conferencias electorales fueron exclusivamente hombres, y en Valparaíso y Viña del Mar sólo en dos ocasiones participó una militante (Isolina Albuquerque) ${ }^{70}$. Además, si bien la mayoría de los escritos de la prensa del partido en este contexto tenía como fin exponer temas relacionados con las elecciones, las artimañas del gobierno o la venta del voto, en ninguno de ellos se hace mención a la reivindicación del sufragio femenino.

El alejamiento de la problemática femenina probablemente respondió al reforzamiento de la organización sindical en que se comprometieron los socialistas desde 1916 (y que se intensificó entre 1917-1918), en un intento por reunir a los trabajadores en organismos con mayor alcance gremial y territorial, proceso que culminó en 1919 cuando el partido alcanzó un rol hegemónico al interior de la Federación Obrera de Chile (FOCH). Quizás por estos motivos, las únicas menciones femeninas de los socialistas porteños hacia 1918 vengan del ámbito laboral. Una pequeña nota que informaba sobre el triunfo de la huelga de los obreros zapateros de Santiago, otorgaba a las mujeres el papel clave del éxito del movimiento ${ }^{71}$. El otro ejemplo, es un artículo publicado en febrero de 1918 en $\mathrm{El}$ Calderero, órgano de la Sociedad Unión de Caldereros, que denunciaba las condiciones laborales a las que se exponían las obreras industriales y culpaba a los obreros varones por

\footnotetext{
${ }^{68}$ El Socialista, Valparaíso, 23 de febrero y 2 de marzo, 1918.

${ }^{69}$ El Socialista, Valparaíso, 16 de marzo, 1918.

${ }^{70}$ El Despertar de los trabajadores, Iquique, 22, 24, 27 y 28 de febrero, 1918; El Socialista, Antofagasta, 6 y 15 de marzo, 11 y 13 de abril, 1918; El Socialista, Valparaíso, 2 de marzo, 1918.

${ }^{71}$ El Socialista, Valparaíso, $1^{\circ}$ de mayo, 1918. Sobre la huelga de los zapateros en la capital, ver Peter DeShazo, Trabajadores urbanos y sindicatos en Chile: 1902-1927, Santiago, DIBAM, 2007, pp. 216-220.
} 
no comprometerse profundamente con la emancipación femenina y con su organización sindical $^{72}$. En este gremio era clara la influencia de los socialistas desde 1916, ejemplo de ello es el caso de Guillermo Castro, militante socialista que llegó a ocupar el cargo de secretario de esta sociedad en 1918.

A lo anterior, se sumaron una serie de factores que debilitaron al POS y, por ende, influyeron en el descenso de su preocupación sobre la problemática femenina, principalmente en el norte salitrero. Uno de éstos fue la intensificación de la represión en contra de las agrupaciones socialistas, tanto por parte de la policía como de organizaciones extra-estatales, como las Ligas Patrióticas, que retomaron sus actividades delincuenciales en Tarapacá y Antofagasta hacia fines de 1918. Si bien estas organizaciones paramilitares se fundaban en la persecución y hostigamiento de los extranjeros residentes en el norte salitrero (principalmente peruanos y bolivianos), también actuaron en contra de los que comprendían como enemigos de los valores nacionales, entre los cuales se encontraban los socialistas, pacifistas e internacionalistas por convicción. En función de estos ideales, y también de la utilización de las Ligas por parte de los sectores dominantes, los socialistas iquiqueños sufrieron en enero de 1919 la destrucción de la imprenta de El Despertar de los Trabajadores $^{73}$. Así también, la movilización obrera en Antofagasta fue entendida como una amenaza al orden público, justificación que utilizó la justicia para ordenar en febrero de 1919 la detención de varios dirigentes del POS y el cierre de la imprenta de El Socialista.

Dentro de los factores que debilitaron la acción socialista, hay que considerar también la crisis salitrera que comenzó en 1918 y que disparó la cesantía, comenzando así un nuevo período de agitación obrera y emigración masiva de trabajadores hacia el centro y sur del país ${ }^{74}$. Una de las consecuencias socio-política de esta crisis fue la creación de la Asamblea Obrera de Alimentación Nacional (AOAN), surgida al alero de la FOCH y donde el POS estuvo profundamente involucrado, llegando a ocupar el cargo de Presidente de la Mesa Directiva el socialista santiaguino Carlos A. Martínez ${ }^{75}$.

Los esfuerzos puestos tanto en el sostenimiento de la estructura partidaria (fuertemente golpeada por la emigración de los obreros salitreros) y en los resguardos frente al incremento de la represión, como también en la organización sindical y social (FOCH y AOAN), transformaron las temáticas tratadas por los socialistas hasta $1918 \mathrm{e}$ incidieron negativamente en el peso que había alcanzado en el partido la problemática femenina.

\footnotetext{
${ }^{72}$ El Calderero, Valparaíso, 3 de febrero, 1918.

73 Sergio González M., Carlos Maldonado y Sandra McGee, "Las Ligas Patrióticas", Revista de Ciencias Sociales, 2, Iquique, 1993, pp. 54-72. A esta ola represiva, hay que sumarle la promulgación de la Ley de Residencia, en noviembre de 1918.

74 Julio Pinto, "Crisis salitrera y subversión social: los trabajadores pampinos en la post Primera Guerra Mundial (1917-1921)" y "Donde se alberga la revolución: la crisis salitrera y la propagación del socialismo obrero (1920-1923)", ambos trabajos en Julio Pinto, Desgarros y utopías en la pampa salitrera. La consolidación de la identidad obrera en tiempos de la cuestión social (1890-1923), Santiago, Lom Ediciones, 2007, pp. 151-182 y pp. 183-232, respectivamente.

75 Sobre la AOAN, ver DeShazo, op. cit., pp. 231-238; Gabriel Salazar, Del poder constituyente de asalariados e intelectuales (Chile, siglos XX y XXI), Santiago, Lom Ediciones, 2009, pp. 40-51; Grez, op. cit., pp. 91-101.
} 
A pesar de que en el norte salitrero la preocupación por los temas femeninos se desvanece, no desaparece del todo. A comienzos de febrero de 1918, los socialistas iquiqueños publicaron un reportaje sobre el papel jugado por las mujeres trabajadoras en el mantenimiento de la producción industrial en la Primera Guerra Mundial ${ }^{76}$. Unas semanas después, otro artículo informaba sobre el reconocimiento del derecho a voto de las mujeres en Inglaterra, acontecimiento considerado como «algo comparable a una liberación de esclavos», ya que, aunque «con menor rigor aparente, esa es también la suerte de la mujer en las naciones modernas que les niegan el voto». El aspecto que llamaba positivamente la atención del articulista, era la actitud del Partido Laborista inglés frente a este hecho, que en vísperas de las elecciones con un nuevo padrón electoral había convocado a las mujeres en general y no sólo a aquellas que eran obreras ${ }^{77}$. Al parecer, la intención de este artículo era internalizar una futura estrategia electoral, porque el mismo no se hace cargo de la situación de las mujeres chilenas ni reivindica el derecho a voto para las mismas.

Como vimos más atrás, para la coyuntura electoral de 1918 en Antofagasta, la apelación a la mujer seguía circunscrita a temas como la educación anticlerical y el apoyo que la mujer debía prestar al obrero organizado. En el periódico de esta agrupación, sólo es posible apreciar un pequeño llamado que se repite en múltiples ediciones de 1918: «Es un asunto de mucha importancia que El Socialista sea leído por el mayor número posible de mujeres que pertenezcan a las clases pobres» ${ }^{78}$. ¿Por qué la lectura de un periódico socialista por parte de las mujeres pobres era un asunto de suma importancia? No se explicita allí, ni tampoco los socialistas antofagastinos dedicaron espacio adicional para explicarlo.

Recién a mediados de 1919 reflota la presencia de los temas femeninos, cuando desde la pampa salitrera de Antofagasta se publica una convocatoria para formar la Sociedad Protección y Cultura de la Mujer ${ }^{79}$. Esta organización dio a conocer sus estatutos en agosto y su declaración introductoria consideraba a la mujer como «el pedestal de toda civilización y sociedad», lo que no tenía correlación con el tratamiento que recibía, cercano al de una esclava, además de ser considerada incapaz de «compartir con el hombre las libertades que la naturaleza ha otorgado a los dos sexos». Para revocar estas desigualdades, esta organización invitaba a integrarse a «toda mujer obrera sin distinción de nacionalidad» $\mathrm{y}$, entre sus puntos principales, se planteaba el objetivo de luchar por la obtención del voto femenino, porque así como la mujer podía desempeñarse en distintas labores, también podía ocupar «puestos legislativos y en los municipios» ${ }^{80}$. En esta sociedad es innegable la influencia del discurso socialista, ya que además de la proyección electoral y política, esta organización apelaba expresamente a la mujer obrera, sumando también el aspecto anticlerical y la crítica a las mujeres que se dedicaban a la prostitución.

A pesar de que los socialistas secundaron esta iniciativa, la formación en Antofagasta de la Sociedad Femenina de Oficios Varios los tomó por sorpresa, por ello, a la

${ }^{76}$ El Despertar de los Trabajadores, Iquique, 3 de febrero, 1918.

${ }^{77}$ El Despertar de los Trabajadores, Iquique, 22 de febrero, 1918.

${ }_{78}^{78}$ Publicado en múltiples ediciones, por ejemplo, en El Socialista, Antofagasta, 5 de junio, 1919.

${ }^{79}$ El Socialista, Antofagasta, 12 de junio, 1919.

${ }^{80}$ El Socialista, Antofagasta, 10 de agosto, 1919. 
vez que saludaban con regocijo su creación, declaraban no haber incidido en ella. Además, aprovecharon esta noticia para publicar un llamado a todas las mujeres trabajadoras a integrarse a ella ${ }^{81}$. En un contexto de debilitamiento de la movilización femenina en el partido respecto a lo ocurrido entre 1915 y 1918, teniendo en cuenta, además, la represión oligárquica en contra del movimiento obrero, la aparición de esta organización se transformó en un importante hito para la revitalización de las mujeres socialistas.

A partir de este hecho la situación cambiaría, llevando al POS a preocuparse nuevamente por el elemento femenino, giro que fue más bien propiciado por la movilización de las propias obreras que por acciones específicas del partido. En noviembre de 1919, Isabel Díaz comunicaba a El Socialista que la Sociedad Protección y Cultura de la Mujer había decidido convertirse en Federación Femenina, contando ya con aproximadamente 250 socias y con más de $\$ 300$ en fondos disponibles. Además, declaraba que esta decisión se había tomado con la intención de reforzar la organización y también para contrarrestar la actitud de «algunos compañeros [que] no reconocen nuestro ideal y quieren coartar la libertad que tenemos nosotras las Mujeres» ${ }^{82}$. Por esos días, el importante dirigente socialista Manuel A. Silva dio una conferencia en Calama, donde invitó «al elemento femenino a secundar esta grandiosa obra de mejoramiento económico, político y social de la clase trabajadora», es decir, integrarse a la FOCH y al partido, y por extensión, a la Federación Femenina ${ }^{83}$. La movilización aumentaba. El 9 de noviembre se creó la Federación Femenina Obrera de Chile-Sección Chuquicamata, con más de 40 afiliadas. Esta importante iniciativa de las mujeres obreras perdió en autonomía cuando se fusionó con la sección masculina, quedando a su alero en términos económicos ${ }^{84}$.

La activación de las mujeres obreras en el interior de la provincia de Antofagasta fue acompañada por la restitución del discurso que veía a éstas como acompañantes de la organización masculina. No obstante, se produjeron algunos importantes cambios, principalmente en el tipo de exhortación hacia las obreras. En agosto de 1920, desde Calama un militante expresaba que era un gran error pensar que la mujer no estaba capacitada para la lucha, aunque reconocía que la mayoría de ellas no participaba en la organización obrera, lo que se debía, según su opinión, «a la desidia de los padres de familia, tutores, hermanos y esposos» ${ }^{85}$. Un mes después, un nuevo artículo refrendaba la crítica hacia los hombres, pero avanzaba más allá, señalando que los «compañeros [...] no pueden ya impedir que ellas hagan su Federación y empiecen una campaña de propaganda a favor de su emancipación» ${ }^{86}$. ¿Quiere decir esto que los hombres (entre ellos los socialistas) fueron un obstáculo para la organización de las obreras? No hemos encontrado ejemplos concretos que prueben esta afirmación, pero la permanencia de esta crítica en la prensa socialista indica, a lo menos, que los trabajadores varones no fueron los más activos promotores de la organización obrera femenina.

\footnotetext{
${ }^{81}$ El Socialista, Antofagasta, 15 de agosto, 1919.

${ }^{82}$ El Socialista, Antofagasta, 10 de noviembre, 1919.

${ }^{83}$ El Socialista, Antofagasta, 11 de noviembre, 1919.

${ }^{84}$ El Socialista, Antofagasta, 14 de noviembre, 1919.

${ }^{85}$ El Socialista, Antofagasta, 10 de agosto, 1920.

${ }^{86}$ El Socialista, Antofagasta, 7 de septiembre, 1920.
} 
Un hecho que funcionó como catalizador de la activación de las mujeres en la organización obrera y socialista, fue la Revolución bolchevique de 1917. En las acciones de las revolucionarias rusas se basaba la exhortación que "Una federada" realizaba a sus compañeras, al señalar: «debemos guiarnos y tomar como ejemplo la acción de la Rusia [...] que ya empieza a conmoverse al impulso de las nuevas ideas de regeneración social» $^{87}$. Esta idea fue acompañada con el incremento en la prensa socialista de las informaciones del proceso revolucionario ruso y de textos bolcheviques alusivos a las mujeres.

En un avance notable en la forma en que los socialistas habían tratado el tema de los derechos políticos de las mujeres en Chile, un artículo de octubre de 1920 planteaba que éstas tenían el «perfecto derecho a ser tomadas muy en cuenta y consultadas en lo que atañe a la acción moralizadora del Gobierno y de las leyes que al respecto se promulguen», dado que a la fecha la mujer tenía conciencia «de cuánto puede, cuánto vale y cuánto pesa en la lucha renovadora en que estamos empeñados». Por lo mismo, era necesario «devolverle todos los derechos y prerrogativas políticas y jurídicas que le corresponden y que nuestras leyes le tienen usurpadas» ${ }^{88}$. Así, por vez primera los socialistas antofagastinos articulaban abiertamente el reconocimiento de las mujeres como sujetos políticos. Esta opinión se apoyaba, sin duda, en el crecimiento de la organización obrera en general y también femenina en Antofagasta, que tenía en el Consejo Femenino de Yungay (FOCH) uno de sus más activos representantes, con 297 socias hacia noviembre de $1920^{89}$.

El crecimiento de la organización de las mujeres obreras que comenzó en 1919, se coronó en enero de 1921, cuando las socialistas de Antofagasta decidieron formar el Partido Obrero Socialista Femenino, sustentado en un programa que contenía la aspiración de educación obligatoria para las mujeres, igualación de derechos civiles y políticos, combate al cohecho, mejoramiento de los salarios femeninos y, por último, prohibición del trabajo infantil. Este partido declaraba que realizaría «todas aquellas medidas de orden político o económico que las necesidades y la experiencia aconsejen, mejorando siempre la condición moral y material del proletariado», además de llevar a cabo «un programa máximo y progresivo hasta obtener la dictadura del proletariado, o sea, la república comunista, de los soviet» ${ }^{90}$. La recepción de la Revolución bolchevique es innegable, así como también la intención de las mujeres socialistas, ya que no se trataba tan sólo de crear una sección femenina del POS, sino que de un partido autónomo con propuestas propias y formas de acción que reforzaran las propuestas socialistas específicamente femeninas. Se trataba de un desplazamiento desde la anterior comprensión de las mujeres como refuerzo de la acción masculina, a la posibilidad de una articulación política estrictamente femenina y con demandas específicas. Sin duda, este cambio se apoyaba en el crecimiento de la

\footnotetext{
${ }^{87}$ El Socialista, Antofagasta, 10 de octubre, 1920.

${ }^{88}$ El Socialista, Antofagasta, 18 de octubre, 1920.

${ }^{89}$ El Socialista, Antofagasta, 22 de diciembre, 1920.

90 El Socialista, Antofagasta, 9 de enero, 1921. Los estatutos en la edición del 10 de enero, 1921. La formación del POS Femenino tuvo como base el Centro de Mujeres Socialistas (creado en 1916), que en diciembre lo conformaban alrededor de 140 militantes (El Socialista, Antofagasta, 22 de diciembre, 1920).
} 
organización obrera de las mujeres antofagastinas, específicamente al interior de la FOCH y del POS.

La intensificación de la movilización obrera que se verificó en el período 19191921, donde hay que anotar la elección como diputados del POS de Luis E. Recabarren y Luis V. Cruz (marzo 1921), transformó la percepción de los hombres socialistas. De la visión complementaria de los primeros años, la mujer pasó a ser comprendida como una parte fundamental del partido. Las acciones desarrolladas por las obreras pampinas en esta nueva etapa llamaron profundamente la atención de sus compañeros varones, llegando a expresar uno de éstos que «ha cambiado tanto que ahora parece que fuera otra mujer, muy distinta a la de ayer». A los ojos de los socialistas, este cambio implicaba que la obrera «se ha renovado completamente, moral y materialmente, llenando su espíritu con la luz de hermosos anhelos y más bellos ideales, y se ha consagrado por entero a la causa de la emancipación proletaria, a la lucha por el triunfo de la Revolución Social». En la práctica, las mujeres sobresalían «prestando su concurso para todo, en la tribuna, en la reunión, en la huelga, ansiosas, siempre de conseguir triunfos y progresos para la organización federal de los obreros» ${ }^{91}$.

Un punto interesante a destacar, es que el aumento de la movilización femenina se registró en un período de alta conflictividad social y represión en contra del movimiento obrero $^{92}$. Es probable que, además de manifestar una situación real, los socialistas se volcaron discursivamente hacia las mujeres como una estrategia para enfrentar las arremetidas patronales y estatales en contra de las organizaciones obreras, intentando con ello salvar las persecuciones a los dirigentes más conocidos. Con todo, es innegable que el POS -y, bajo su dirección, también la FOCH- modificó su discurso hacia las militantes y su aproximación hacia las mujeres obreras ${ }^{93}$.

El avance de la organización femenina fue tal, que a mediados de 1921 una militante proponía que en el futuro Congreso de la $\mathrm{FOCH}$, a realizarse en diciembre de aquel año en la ciudad de Rancagua (evento donde esta federación se incorporó a la Profintern o Internacional de los Sindicatos Rojos, símil sindical de la III ${ }^{a}$ Internacional), la mujeres federadas sesionaran autónomamente para tratar temas estrictamente femeninos. Entre éstos se encontraban: el mejoramiento de las condiciones sociales de las mujeres, la creación de un Comité Nacional Central que coordinara las acciones de las federadas, la publicación de un periódico feminista, el establecimiento de un programa con las acciones que debían seguir las mujeres para lograr la Revolución Social, una declaración sobre la inutilidad del matrimonio legal burgués y la formación de una organización infantil de ambos sexos. Todo esto estaba en función de «darse una orientación que acelere la marcha

\footnotetext{
${ }^{91}$ El Socialista, Antofagasta, 6 de abril, 1921.

${ }^{92}$ En febrero de 1921 se produjo la matanza obrera en la oficina salitrera de San Gregorio, en la provincia de Antofagasta. Sobre esta matanza ver el trabajo de Floreal Recabarren, crítico de la actuación en este hecho de federados y socialistas, La Matanza de San Gregorio. 1921: crisis y tragedia, Santiago, Lom Ediciones, 2010.

${ }^{93}$ En estas fechas comenzó a experimentarse un importante avance femenino al interior de la FOCH. Tanto así que en 1923 existían en todo el país 47 Consejos Federales integrados por mujeres, 7 de ellos de ambos sexos y 40 exclusivamente femeninos. Boletín de la Oficina del Trabajo. Los organismos técnicos del trabajo, Santiago, Imprenta Santiago, 1923, pp. 188-192.
} 
de nuestra revolución emancipadora» ${ }^{94}$. No es casual que esta propuesta se publicara en la sección "Algo de Feminismo", del periódico socialista de Antofagasta, un apartado difícil de imaginar unos años atrás.

El autonomismo que presenta el ejemplo anterior, se ve reforzado con una articulación más elaborada que es visible entre las/los socialistas sobre el estado de las relaciones de género en la sociedad chilena de la época. Un artículo enviado desde Calama, definía a la mujer como un sujeto que tenía al conjunto de la sociedad en su contra. La autora señalaba que la explotación de la mujer proletaria era mayor que la de su par masculino, debido a que aquella tenía que ocuparse de las labores domésticas. Denunciaba el patriarcado al que se veían enfrentadas las mujeres en las relaciones familiares, al que se sumaban exigencias culturales que aumentaban simbólicamente la explotación femenina, como el requisito de la virginidad sexual u "honor". Además de la inexistencia de derechos políticos. La solución proyectada era clara: «Cuando el socialismo imponga su doctrina [...], entonces recién la mujer podrá gozar de los derechos que el hombre por egoísmo le niega a ejercerlos» ${ }^{95}$.

«Hasta hoy no se ha dado la preferencia que merece a la acción de la mujer en el movimiento sindical comunista», comenzaba críticamente una editorial de El Socialista de febrero de 1922, a poco más de un mes de la decisión de transformar al POS en Partido Comunista de Chile. Según el editorialista, si bien era claro que la mujer socialista había logrado un espacio en las acciones del partido y también que se había avanzado en el reconocimiento de las condiciones femeninas, la realidad dictaba que se mantenían ciertas trabas que impedían su desarrollo político y gremial, las cuales se incubaban en la práctica de sus compañeros varones. Por lo mismo, exigía que «cuando las compañeras demanden nuestro concurso para emprender [...] un paso más en la lucha social, se encuentren con nuestra más decidida cooperación y no con nuestro egoísmo o nuestro espíritu de absorción». La editorial concluía recomendando la necesidad «que todos los trabajadores piensen mucho en esto. Que recapaciten mucho, hasta comprender el interés de la acción femenina» ${ }^{96}$.

Esta editorial es una buena síntesis del camino de politización seguido por las mujeres socialistas entre 1912 y 1922 . Por una parte manifiesta su reconocimiento como sujeto político, y por otra, da cuenta de la persistencia entre los militantes varones de ciertas actitudes propias de una relación de género no igualitaria. Al mismo tiempo, indica la incomodidad, no siempre expresada, que provocaban entre los socialistas (ahora comunistas) las conductas contrarias a la igualdad en que se basaba su programa. Se trataba de una relación compleja, no exenta de conservadurismo y discriminación, pero que en último término era reconocida como una tarea no consumada. Convivían, por tanto, rasgos de adelanto y permanencia. Tras una década de internalización de la problemática femenina, igualitarismo y conservadurismo estaban todavía presentes en la cultura política

\footnotetext{
${ }^{94}$ El Socialista, Antofagasta, 1 de mayo, 1921.

${ }^{95}$ El Socialista, Antofagasta, 28 de julio, 1921.

${ }^{96}$ El Socialista, Antofagasta, 11 de febrero, 1922.
} 
socialista, dando cuenta así de una tensión en desarrollo, la misma a la que esperaba un largo camino en los próximos años.

\section{Conclusiones}

Como uno de los objetivos basales del POS era la construcción de una sociedad igualitaria y justa, rápidamente la situación de la mujer se manifestó en su discurso y en sus acciones. Por ello, la politización femenina fue uno de los puntos que el partido integró y promovió al interior del mundo obrero. No se trató, sin embargo, de un proceso unívoco.

Las particularidades del movimiento obrero en las diferentes ciudades donde el partido se desenvolvió, incidieron en la aproximación de éste a la problemática femenina. Incidió también la actuación de las mujeres socialistas. Así, en aquellos lugares donde el espacio laboral fue mayoritariamente ocupado por hombres, la temática femenina estuvo vinculada al anticlericalismo y se adoptó una postura que comprendió la movilización de las mujeres como un refuerzo de la lucha de los obreros varones. Este fue el caso del norte salitrero (y en cierta medida de Magallanes). En cambio, en centros urbanos como Valparaíso, el anticlericalismo no ocupó tanto los esfuerzos de las mujeres socialistas como sí lo hizo la construcción de organizaciones obreras.

Un aspecto común en los primeros años de la acción socialista fue la exaltación del rol cultural que debía jugar la mujer en tanto formadora de las generaciones venideras, crucial para despertar en los sujetos el espíritu de justicia social. La referencia a la maternidad puede expresar la persistencia entre los socialistas de la comprensión del hogar como "el" espacio femenino, pero también pudo ser el referente discursivo más a mano para vincular a las mujeres con los desafíos que imponía el socialismo. De ahí, entonces, que se relacionara constantemente la maternidad con la politización.

El crecimiento que experimentó el movimiento obrero hacia fines de la década de 1910 y la influencia que ganó el POS en él, tuvieron como consecuencia la modificación del papel de las mujeres al interior del partido. El caso más llamativo fue el de Antofagasta, donde las mujeres pasaron de ser una preocupación secundaria a ocupar cada vez más espacios al interior del partido. Ejemplo de ello, fueron las iniciativas orgánicas estrictamente femeninas y, también, el incremento de noticias y artículos de opinión en la prensa partidista. De esta forma, la sección antofagastina pasó de tener en los primeros años del partido un discurso marcadamente conservador a convertirse en el puntal de la propaganda a favor del avance de las posiciones feministas, articulándose desde allí, interesantes acercamientos a las relaciones de género y al derecho a voto de la mujer.

Con este trabajo hemos intentado poner de manifiesto las prácticas y discursos tanto de las mujeres socialistas como de sus compañeros varones. Igualmente, intentamos dar cuenta de la existencia de acciones políticas llevadas a cabo por las mujeres, a pesar de su exclusión legal y de las trabas sociales y culturales que existían en el primer cuarto del siglo XX. De esta manera, esperamos haber contribuido al estudio de las formas de politización obrera y, específicamente, a la historia de las mujeres trabajadoras que se inclinaron por la construcción del socialismo, dando los primeros impulsos al feminismo de izquierda que se

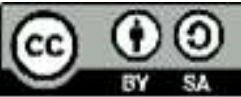


desarrollaría durante el resto del siglo y que, con tópicos contemporáneos, extiende sus luchas hasta nuestros días.

Recibido: 22 diciembre 2015 Aceptado: 3 marzo 2016

\section{FUENTES Y BIBLIOGRAFÍA}

\section{Fuentes}

a. Compilaciones y archivos manuscritos:

- CRuZAt, Ximena y EduARdo Devés (comp.), Recabarren. Escritos de prensa. Tomo 3, 19141918, Santiago, Nuestra América y Terranova Editores, 1986.

- Epistolario Recabarren, Archivo Histórico Nacional, Fondos Varios, vol. 1157.

b. Prensa:

- Acción Obrera, Santiago, 1916.

- El Chileno, Santiago, 1914.

- $\quad$ El Despertar de los Trabajadores, Iquique, 1912-1921.

- El Socialista, Antofagasta, 1916-1922.

- $\quad$ El Socialista, Punta Arenas, 1913-1917.

- El Socialista, Valparaíso, 1915-1918.

- Familia, Santiago, 1914.

- La Aurora, Taltal, 1916-1917.

- La Defensa Obrera, Valparaíso, 1915.

- La Razón, Santiago, 1913.

- La Unión, Valparaíso, 1913-1915.

- La Voz Socialista, Santiago, 1913.

c. Otras:

- LóPEz, Osvaldo, Diccionario biográfico obrero, Santiago, Imprenta y Encuadernación Bellavista, 1912. Disponible en Internet:

- $\quad$ http://www.memoriachilena.cl/archivos2/pdfs/MC0066481.pdf, (revisado en abril de 2015).

\section{Bibliografía}

- Brito, AlEJANDRA, "Del rancho al conventillo. Transformaciones en la identidad popular femenina Santiago de Chile, 1850-1920", en Lorena Godoy, Elizabeth Hutchison, Karin Rosemblatt y M. Soledad Zárate (eds.), Disciplina y desacato. Construcción de identidad en Chile, siglos XIX y XX, Santiago, SUR-CEDEM, 1995, pp. 27-69.

- DEShAZO, PETER, Trabajadores urbanos y sindicatos en Chile: 1902-1927, Santiago, DIBAM, 2007. 
- Godoy, EduARdo, La Huelga del Mono. Los anarquistas y las movilizaciones contra el retrato obligatorio (Valparaíso, 1913), Santiago, Quimantú, 2014.

- González M., Sergio, Carlos Maldonado y SANDra McGee, "Las Ligas Patrióticas", Revista de Ciencias Sociales, 2, Iquique, 1993, pp. 54-72.

- Grez T., SERGIO, Los anarquistas y el movimiento obrero. La alborada de "la Idea" en Chile, 1893-1915, Santiago, Lom Ediciones, 2007. , Historia del Comunismo en Chile. La era de Recabarren (1912-1924), Santiago, Lom Ediciones, 2011.

- GARrido, EugEnia, "Los orígenes de Viña del Mar y su proceso de industrialización. Un caso específico: Lever, Murphy y Cía.", Archivum. Revista del Archivo Histórico Patrimonial, año $\mathrm{V}, \mathrm{n}^{\mathrm{o}}$ 6, Viña del Mar, 2004, pp. 74-87.

- HutChison, Elizabeth, Labores propias de su sexo. Género, política y trabajo en Chile urbano, 1900-1930, Santiago, Lom Ediciones, 2006.

- $\quad$ Illanes O., MARÍA ANGÉliCA, Nuestra historia violeta. Feminismo social y vidas de mujeres en el siglo XX: una revolución permanente, Santiago, 2012.

- $\quad$ KiRKWOOd, Julieta, Ser política en Chile, Santiago, Lom Ediciones, 2010.

- $\quad$ Lobato, MirTa, La prensa obrera, Buenos Aires, Edhasa, 2009.

- NAZER, RICARDO Y JAIME ROSEMBLIT, "Electores, sufragio y democracia en Chile: una mirada histórica", Mapocho, n 48, Santiago, segundo semestre de 2000, pp. 215-228.

- PALOMERA, ADrianA, "Subjetividad e identidad política y social de la mujer en la prensa anarquista de comienzos del siglo XX", Olga Ulianova (ed.), Redes políticas y militancias, Santiago, Ariadna-USACH, 2009, pp. 31-58.

- PAlOMERA, AdRIANA y AlejANDRA PINTO (comp.), Mujeres y prensa anarquista en Chile (1897-1931), Santiago, Ediciones Espíritu Libertario, 2006.

- PINTO, JULIO, "Socialismo y salitre: Recabarren, Tarapacá y la formación del Partido Obrero Socialista", Historia, vol. 32, Santiago, 1999, pp. 315-365.

- __ Desgarros y utopías en la pampa salitrera. La consolidación de la identidad obrera en tiempos de la cuestión social (1890-1923), Santiago, Lom Ediciones, 2007.

- $\quad$ de la identidad obrera en Chile", Hispanic American Historical Review, 86:4, 2006, pp. 707745 .

- __ Luis Emilio Recabarren. Una biografía histórica, Santiago, Lom Ediciones, 2013.

- Pinto, JUlio Y VeRónICA VALDIVIA, ¿Revolución proletaria o querida chusma? Socialismo y Alessandrismo en la pugna por la politización pampina (1911-1932), Santiago, Lom Ediciones, 2001.

- Recabarren, Floreal, La Matanza de San Gregorio. 1921: crisis y tragedia, Santiago, Lom Ediciones, 2010.

- SAlAZAR, GABRIEL, Del poder constituyente de asalariados e intelectuales (Chile, siglos XX y XXI), Santiago, Lom Ediciones, 2009.

- TORRES, ISABEL, El imaginario de las elites y los sectores populares. 1919-1922, Santiago, Editorial Universitaria, 2010.

- Urbina, MARÍA XIMENA, "Chalets y chimeneas: los primeros establecimientos industriales viñamarino, 1870-1920”, Archivum, año IV, n 5, Viña del Mar, pp. 173-196.

- ZulOAGA, LuIS, "De la prestación del trabajo en general y particularmente por los criados domésticos", Memoria de prueba para optar al grado de Licenciado en la Facultad de Leyes y Ciencias Políticas de la Universidad de Chile, Santiago, Imprenta de "El Pueblo", 1911.

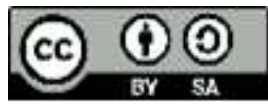

